\title{
YOUNG LARVAE OF ECITON (HYMENOPTERA: FORMICIDAE: DORYLINAE)'
}

\author{
By George C. Wheeler and Jeanette Wheeler \\ 3358 NE 58th Avenue, \\ Silver Springs, Florida 32688
}

\begin{abstract}
I. INSTARS
In our previous studies of ant larvae we have been concerned primarily with generic characterizations and differences based on mature larvae. We described immature stages when available, which wasn't often. And even when we did, we didn't know the instars. Never have we had a complete larval series from egg to semipupa. Yet many authors have stated quite glibly the number of larval instars. At least it seems glib to us, for we consider it hard work to establish the number of instars. To do this we require that following specimens: a first-instar larva inside an egg ready to hatch; a second instar larva inside a first ready to moult; a third-instar inside a second-instar ready to moult; etc.; and finally a mature larva. How can we prove maturity? By comparison with a semipupa, which will reveal all characters of a mature larvae except shape. For further confirmation one should have a worker pupa or a worker to verify size. The identification of sexual larvae presents a further complication. If the larva is larger than a worker semipupa it is probably a sexual or at least a queen. In most species we have not been able to recognize younger sexual larvae.

In polymorphic species (e.g., Eciton, Atta, Acromyrmex, Camponotus) such procedures are even more difficult. How can one tell whether a small larva is a young major or a mature minum or whether a large larva is a half-grown major or a mature intermediate?

Two interesting papers afford a partial solution to this problem: Tafuri (1955) on Eciton hamatum and Lappano (1958) on E. burchelli

Eciton is an ideal genus for such a study: there can be no mixing of broods; except for one all-sexual brood per year, all larvae will
\end{abstract}

'Manuscript received by the editor June 30, 1986. 
become workers. All one needs to determine, then, is whether the larvae in such a brood foreshadow adult polymorphism, and if so, how? The solution depends upon the fact that at the middle of the statary phase the queen lays during one week a single batch of 60,000 to 130,000 eggs and then no more until the next statary phase.

"In $E$. hamatum the adult polymorphic workers form a continuous series from the smallest worker minor to the largest soldier form.... Besides differences in size there are apparent qualitative differences in this series marked primarily by the exceptional hooked manidbles and head pattern of the major workers." (Tafuri 1955: 32.) In the larvae, however, such differences "are not noticeably apparent." Any distinction of growth stages (i.e. nomadic days) is impossible on the basis of body size alone, because of overlapping. The larvae likewise form a smooth series from the smallest to the largest forms. The author therefore based his determination of larval age (in nomadic days) on the allelomorphic growth of the imaginal leg discs.

"[It] is highly probable that the largest larvae of any stage have developed from the eggs first to be laid and first to hatch and represent the potential major workers of the mature brood. Similarly, the smallests [larvae] presumably develop from the eggs last to be laid and last to hatch and represent the potential workers minima of the mature brood." (Lappano 1958: 49).

From these two articles we get the impression that larval development in Eciton is a smooth process from hatching to pupation without any such interruptions as molts. The word "instar" is not found in either of these articles.

So we re-examined our supply of doryline larvae and found graded series of larvae of Eciton hamatum sent to us by the late Dr. T. C. Schneirla (including some of the sample studied by Lappano) from Barro Colorado Island (Panama) and a similar supply of $E$. burchelli larvae collected in Trinidad by Dr. N. A. Weber.

The great advantage of the Tafuri/Lappano method is that it requires no technique and can be applied to either living or preserved material. However, after applying our tedious technique (Wheeler and Wheeler 1960) of cleaning, staining and mounting in balsam, we found that we had the prerequisite for identifying all instars, except the mature larva, which we had already studied (Wheeler and Wheeler 1984). We should warn, however, that the 
preparation of these immature was the most difficult we have ever experienced.

\section{INTERSPECIFIC DIFFERENCES}

Whenever we have had two or more species in the same genus, we have either given a complete description of each or at least mentioned differences. We have not been willing to go beyond that, because we did not know the extent of intranidal or internidal or intraspecific differences. Here at last, we have series of Eciton burchelli and $E$. hamatum which embolden us to make a tentative comparison. Table 1 gives a few characters which can be measured for each instar in each species. The "spiracle diameter" which we have not mentioned previously, is the diameter of the atrium and not of the opening into it.

\section{Eciton burchelli Westwood}

Figure 1

Egg. About $0.3 \times 0.54 \mathrm{~mm}$.

First Instar Larva. Length $0.59-0.9 \mathrm{~mm}$ long (average 0.73 $\mathrm{mm}$ ). Head greater in diameter than body which tapers to the posterior end. Anus subterminal. Segmentation distinct. Spiracles about $0.001 \mathrm{~mm}$ in diameter. Entire integument sparsely spinulose, the spinules minute and isolated. Body hairs lacking. Cranium subcircular. Antennae minute, just above midlength of cranium. Head hairs lacking. Labrum arcuate, about 1/4 width of cranium; with a few spinules and sensilla on and near ventral surface. Mandible with straight apical tooth which is feebly sclerotized, remainder not sclerotized. Maxilla broadly paraboloidal and appearing adnate; palp represented by 7 sensilla in a loose cluster; galea represented by 2 sensilla. Labial palp represented by 3 sensilla; opening of sericteries a short transverse slit.

Second Instar Larva. Length (through spiracles) $0.9-1.5 \mathrm{~mm}$ (average $1.2 \mathrm{~mm}$ ). Head same diameter as $\mathrm{T} 1$ and $\mathrm{AV}$, the widest parts of the body. Spiracles about $0.003 \mathrm{~mm}$ in diameter. Entire integument spinulose, the spinules moderately abundant and isolated. Body hairs 0.006-0.012 mm long; few, most on T1, fewer on $\mathrm{T} 2$ and T3. Cranium subhexagonal; integument with a few spinules. Antennae just above midlength of cranium. About 30 head hairs; 


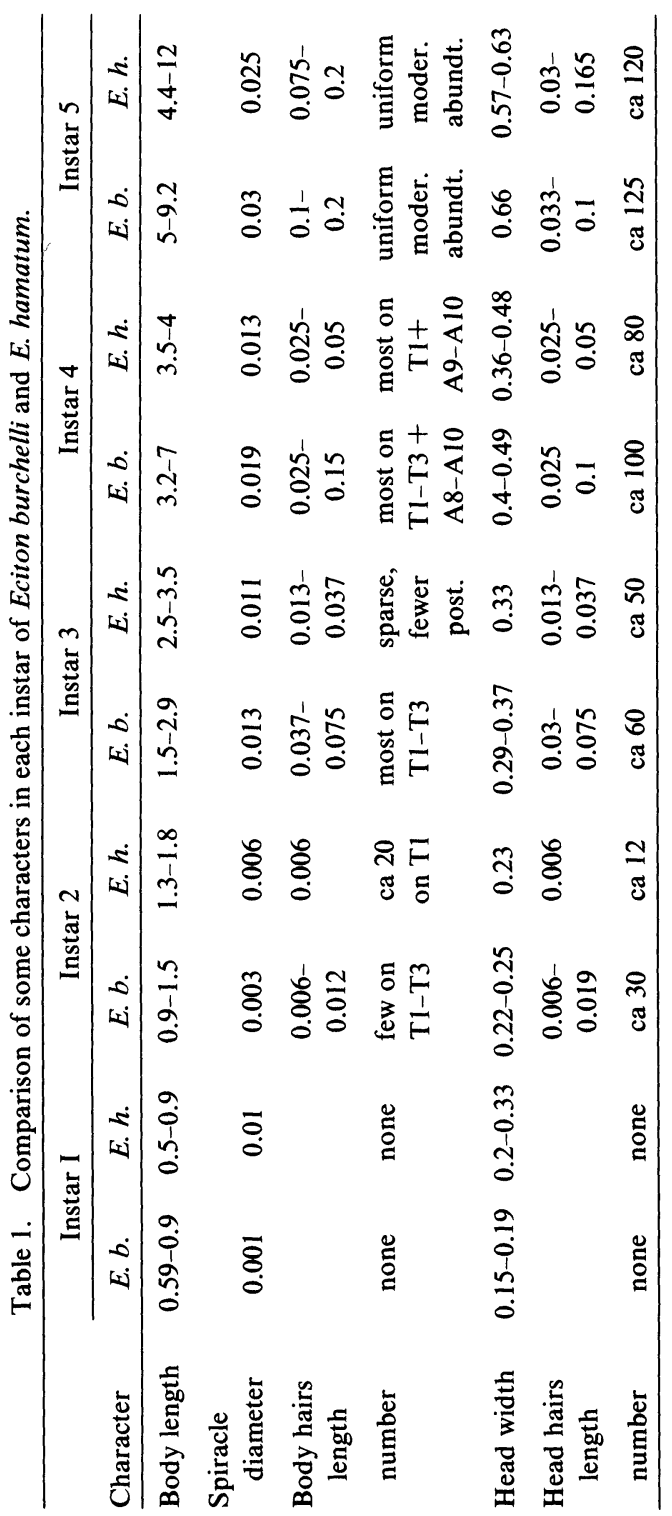




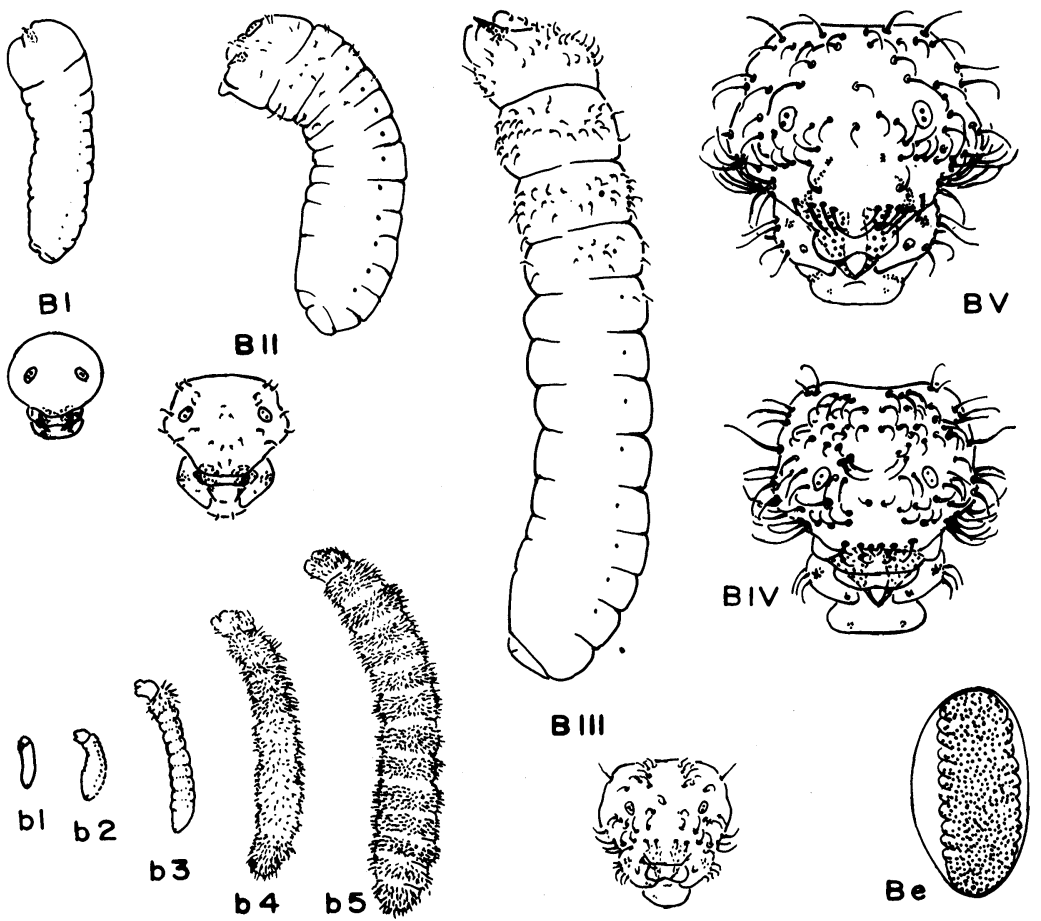

Figure 1. Eciton burchelli. BI, first instar larva; BII, second instar larva; BIII, third instar larva; BIV, head of fourth instar larva; BV, head of fifth instar (= mature) larva. Side views, $\times 38$; head in anterior view, $\times 50$. Be, egg nearly ready to hatch, $\times 38$. b1-b5, larvae of the five instars in side view to show relative sizes, $\times 9$.

0.006-0.019 mm long; simple. Labrum feebly bilobed. Otherwise similar to first instar larva.

Third Instar Larva. Length (through spiracles) $1.5-2.9 \mathrm{~mm}$. Spiracles about $0.013 \mathrm{~mm}$ in diameter. Integumentary spinules more conspicuous and in rows. Body hairs 0.037-0.075 mm long; more numerous but largely confined to thorax. Cranium subhexagonal and with bulging genae. Head hairs $0.036-0.075 \mathrm{~mm}$ long, slender and flexuous; some dorsal hairs curved downward and a few ventral upward; about 60 present. Labrum with transverse rows of spinules on anterior and posterior surfaces on and adjacent to ventral surface; median sulcus with about 10 sensilla on and near ventral surface. Mandible with apical tooth slightly curved medially and with 
medial border erose. Maxilla with apex narrowly paraboloidal and bearing rather long spinules in short transverse rows; palp represented by a cluster of 8 sensilla; galea a slight elevation with 2 sensilla. Anterior surface of labium with minute spinules in short transverse rows. Otherwise similar to second instar larva.

Fourth Instar Larva. Length (through spiracles) $3.2-7 \mathrm{~mm}$. Diameter uniform. Spiracles about $0.019 \mathrm{~mm}$ in diameter. Integument with minute spinules in transverse rows. Body hairs 0.025-0.15 $\mathrm{mm}$ long; on all somites but most numerous on T1-T3 and AVIIIAX. Head hairs 0.025-0.1 mm long; about 100; several ventral hairs curved upward. Labrum with lateral borders sinuate. Maxillary palp represented by a cluster of 9 sensilla; galea a short sclerotized frustum with 2 apical sensilla. Labium with anterior surface bearing numerous short transverse rows of spinules; opening of sericteries a transverse slit in the bottom of a depression. Otherwise similar to third instar larva.

Mature larva. Length (through spiracles) 5-9.2 mm. Compared to E. hamatum in our 1984: 270.

Material studied: numerous larvae from Trinidad, courtesy of Dr. N. A. Weber.

\section{Eciton hamatum (Fabricius)}

Fig. 2

Egg. About $0.25 \times 0.5 \mathrm{~mm}$.

First Instar Larva. Length $0.5-0.9 \mathrm{~mm}$. Head of same diameter as T1; body straight, diameter decreasing posteriorly. Spiracles about $0.001 \mathrm{~mm}$ in diameter. Entire integument spinulose, the spinules minute and isolated. No body hairs. Cranium transversely subelliptical. Antennae above midlength of cranium. No head hairs. Labrum cresentic. Mandibles subtriangular, with straight apical tooth, feebly sclerotized. Maxilla with broadly paraboloidal apex, appearing adnate; palp represented by a cluster of 6-8 sensilla; galea represented by 2 sensilla. Labial palp represented by 3 sensilla; opening of sericteries very short.

Second Instar Larva. Length (through spiracles) $1.3-1.8 \mathrm{~mm}$. Body of nearly uniform diameter. Spiracles $0.006 \mathrm{~mm}$ in diameter. Integument coarsely spinulose, the spinules isolated. Body hairs $0.006 \mathrm{~mm}$ long, simple, few, mostly on venter of T1. Cranium transversely subelliptical. Head hairs about $0.006 \mathrm{~mm}$ long, simple, about 


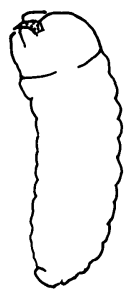

HI
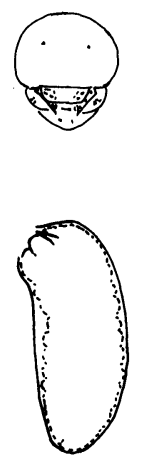

He

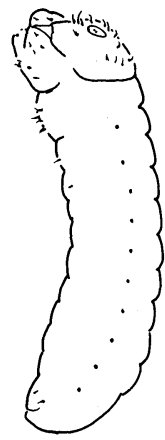

HII
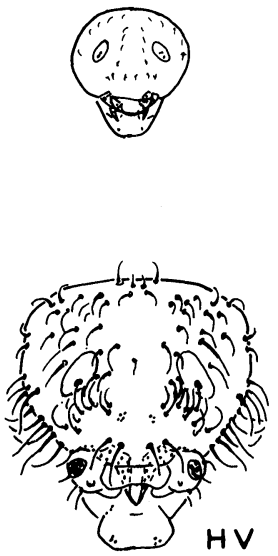
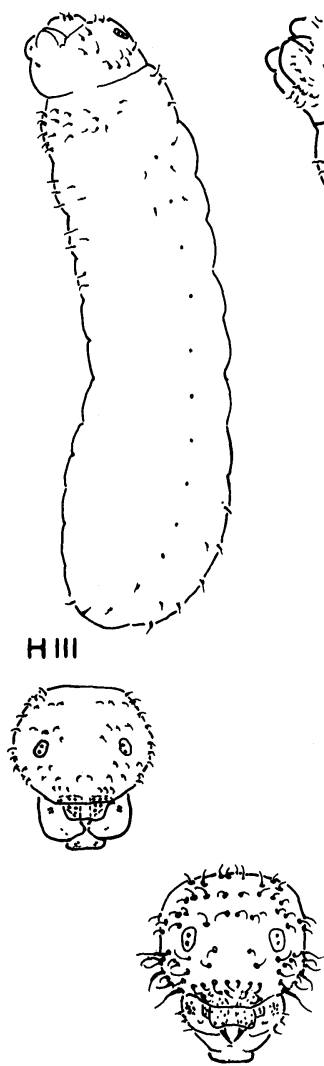
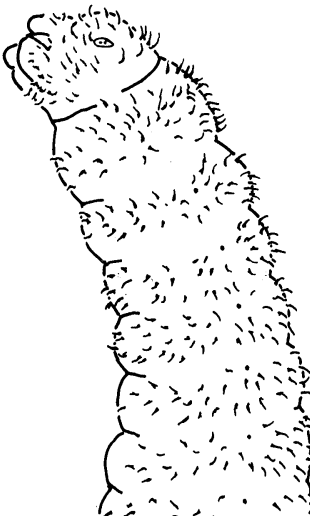

$j=$
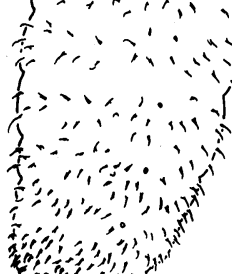

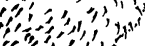

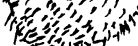

HIV

Figure 2. Eciton hamatum. HI, first instar larva; HII, second instar larva; HIII, third instar larva; HIV, fourth instar larva; HV, head of fifth instar (= mature) larva. Side views, $\times 38$; heads in anterior view, $\times 50$. He, larva inside egg with mouth parts breaking shell, $\times 38$.

12. Maxillary palp represented by a cluster of 10 sensilla. Otherwise similar to first instar larva.

Third Instar Larva. Length (through spiracles) $2.5-3.5 \mathrm{~mm}$. Widest at AVII. Spiracles about $0.01 \mathrm{~mm}$ in diameter. Body hairs 0.013-0.037 mm long, most on thorax and AI and a few of AVI-AX. Cranium slightly broader than long. Head hairs $0.013-0.037 \mathrm{~mm}$ long, about 50. Labrum feebly bilobed. Mandible with apical half more narrowly tapered to a sharp point, apex straight. Maxillary 
palp a cluster of 8 sensilla. Labium with a few minute spinules medially. Otherwise similar to second instar larva.

Fourth Instar Larva. Length (through spiracles) $3.5-4 \mathrm{~mm}$. Spiracle diameter about $0.013 \mathrm{~mm}$. Body hairs $0.025-0.05 \mathrm{~mm}$ long, sparse, most numerous on T1 and AIX-AX. Head hairs 0.025-0.05 $\mathrm{mm}$ long; some dorsal hairs curved downward, few ventral upward; about 100. Labrum bilobed and with sinuate lateral borders; with a few spinules medioventrally. Mandible with apical half tapering to a narrow sharp point and slightly curved medially. Maxillary palp a cluster of 7 sensilla. Otherwise similar to third instar larva.

Fifth Instar Larva = Mature Larva. Length (through spiracles) 4.4-12.1 mm. Spiracles about $0.025 \mathrm{~mm}$ in diameter. Entire integument densely and coarsely spinulose, the spinules rather long and the rows so close together that the spinules overlap. Body hairs moderately numerous; $0.075-0.2 \mathrm{~mm}$ long, longest around anus. Cranium with entire integument spinulose, the spinules isolated or in rows. Head hairs $0.033-0.165 \mathrm{~mm}$ long; about 120 ; some ventral hairs curved strongly upward. Labrum with a few sensilla ventromedially; spinulose, the spinules minute and isolated or in short rows, on all surfaces. Mandible with 3-4 small denticles on apical half. Maxilla broadly paraboloidal and appearing adnate, entire surface spinulose, the spinules isolated or in short rows; palp a slightly elevated sclerotized cluster of 8 sensilla; galea a small sclerotized cone with 2 apical sensilla. Labium with entire surface spinulose, the spinules isolated or in short rows. Otherwise as in the fourth instar larva. See our 1984: Fig. 9 on p. 271.

Material studied: numerous larvae from Barro Colorado Island, Panama, courtesy of the late Dr. T. C. Schneirla.

Our tentative conclusions are:

1. In each species instars may be distinguished by spiracle diameter; body hair length and distribution; head hair length and number.

2. The two species are indistinguishable in the first and fifth instars. In the second instar they may be separated by a spiracle diameter; uniformity in length and distribution of body hairs; length and number of head hairs. In instar three: length and distribution of body hairs; length and number of head hairs. In the fourth instar: spiracle diameter; distribution and uniformity of length of body hairs. 
Literature Cited

LAPPANO, ElEANOR R.

1958. A morphological study of larval development in polymorphic all-worker broods of the army ant Eciton burchelli. Insectes Sociaux 5: 31-66.

TAFURI, J. F.

1955. Growth and polymorphism in the larva of the army ant (Eciton (E.) hamatum Fabricius). Jour. New York Entomol. Soc. 63: 21-41.

WheEleR, G. C. AND JeANetTe WheELER.

1960. Techniques for the study of ant larvae. Psyche 67: 87-94.

1984. The larvae of the army ants: a revision. J. Kansas Entomol. Soc. 57: 263-275. 

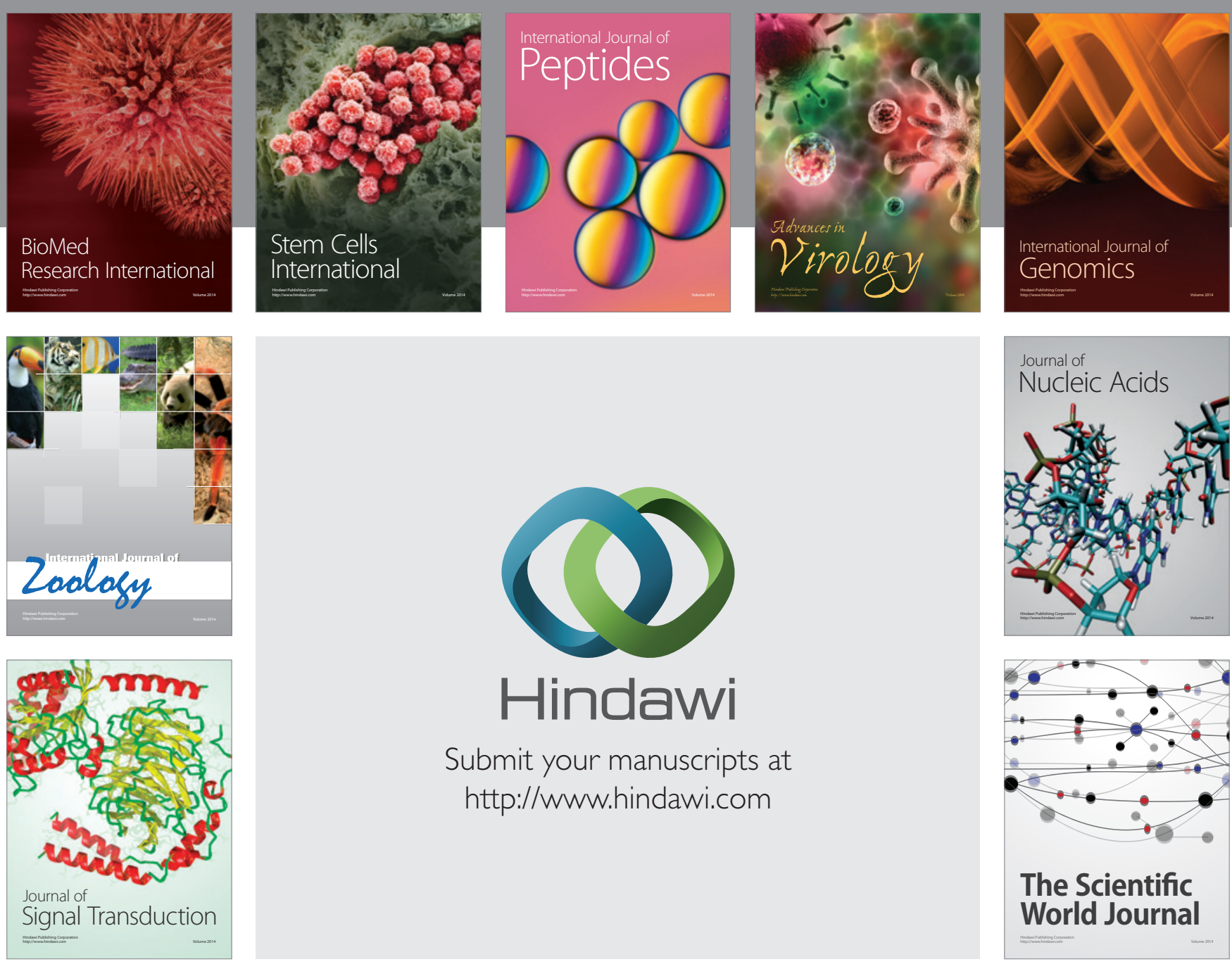

Submit your manuscripts at

http://www.hindawi.com
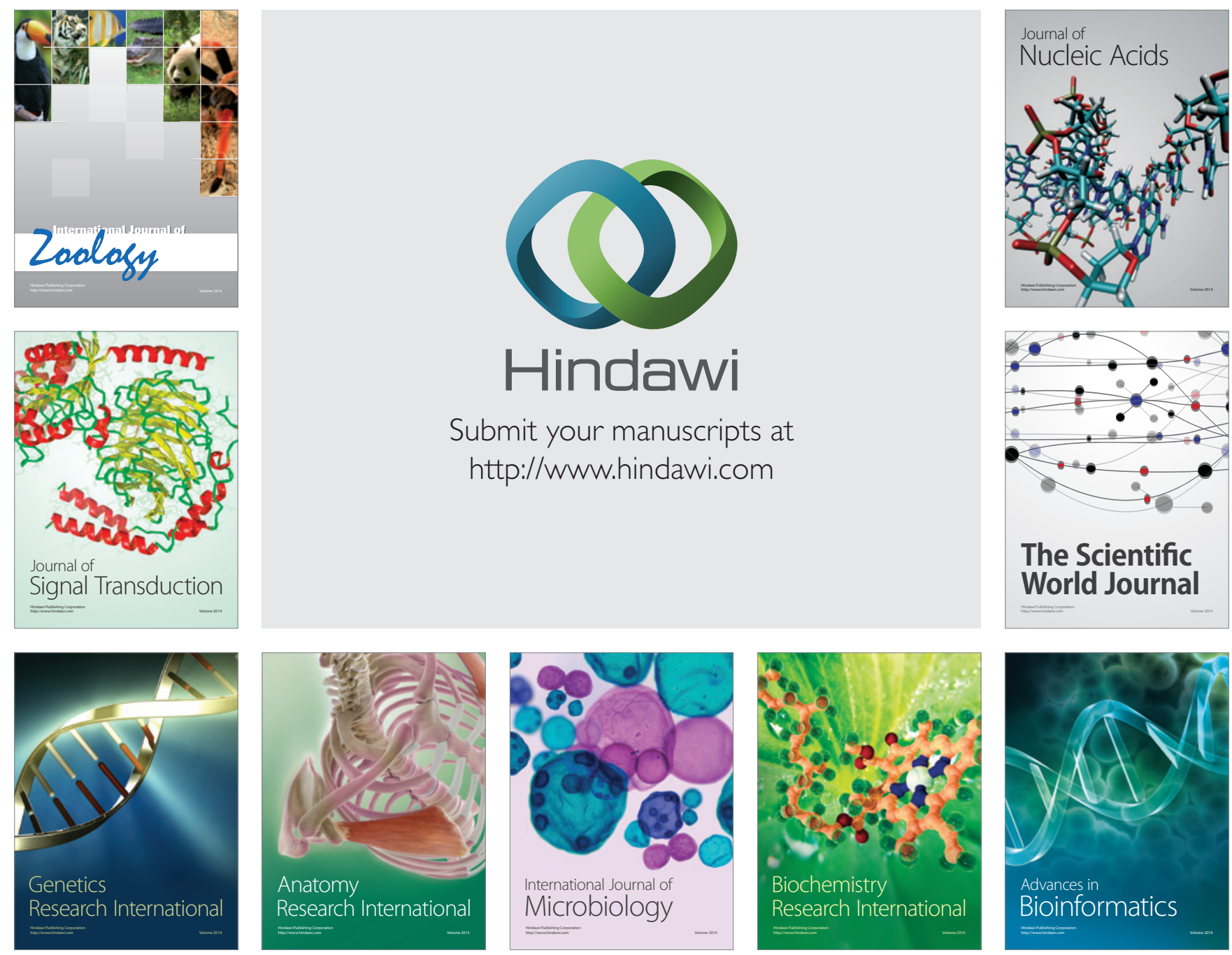

The Scientific World Journal
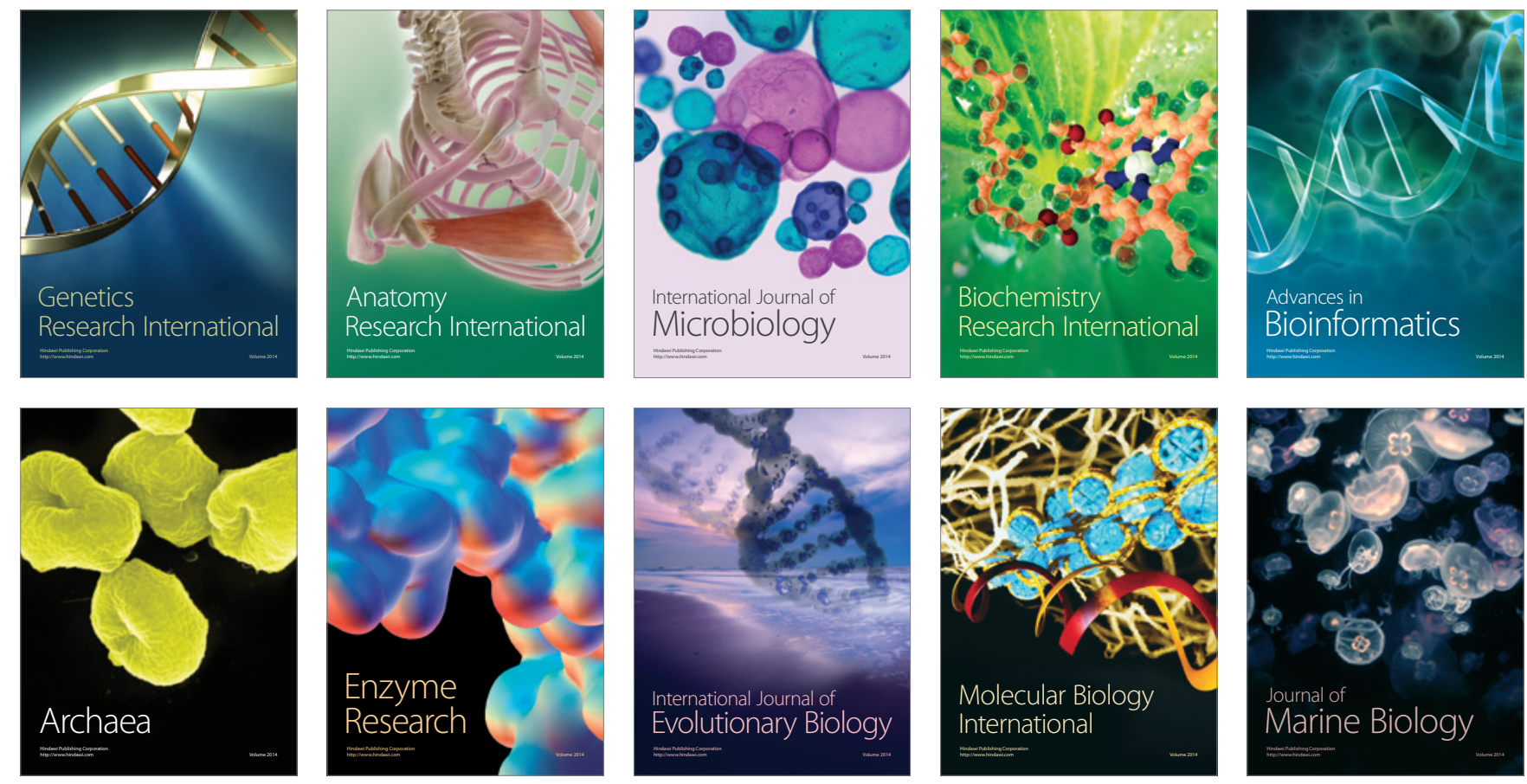